\title{
Comparative Study of Ultrasound and Computerized Tomography for Nephrolithiasis Detection
}

\author{
Sharad Kondekar ${ }^{1}$, Iqbal Minne ${ }^{2}$ \\ ${ }^{1}$ Assistant Professor, Department of Radiodiagnosis, Indian Institute of Medical Science and Research, Wardui, Tq. Badnapur, \\ Dist. Jalna, Maharashtra, ${ }^{2}$ Senior Resident, Department of Radiodiagnosis, Indian Institute of Medical Science and Research, \\ Wardui, Tq. Badnapur, Dist. Jalna, Maharashtra, India
}

Corresponding author: Dr. Iqbal Minne, Senior Resident, Department of Radiodiagnosis, Indian Institute of Medical Science and Research, Wardui, Tq. Badnapur, Dist. Jalna, Maharashtra, India

DOI: http://dx.doi.org/10.21276/ijcmsr.2020.5.2.2

How to cite this article: Sharad Kondekar, Iqbal Minne. Comparative study of ultrasound and computerized tomography for nephrolithiasis detection. International Journal of Contemporary Medicine Surgery and Radiology. 2020;5(2):B4-B7.

\section{A B S T R A C T}

Introduction: Nephrolithiasis is occurrence of renal calculi produced by an interference in balance between solubility and precipitation of salts in urinary tract and in the kidneys. CTU was exposed to be extremely sensitive and specific for ureteric calculi. Study aimed to determine the (i) sensitivity and specificity of ultrasound (USG) in the detection of urinary tract calculi, (ii) size of renal calculi detected on USG and comparing with CTU, and (iii) size of renal calculi not seen on USG but detected on computed tomography urogram (CTU).

Material and Methods: A total of 150 patients' USG and CTU were compared for existence of calculi. Sensitivity, specificity, accuracy, positive predictive value and negative predictive value of USG were calculated with CTU as the gold standard.

Results: From the 150 sets of data collected, 45 calculi were identified on both USG and CTU. The sensitivity and specificity of renal calculi finding on USG were $53 \%$ and $85 \%$ respectively. The mean size of the renal calculus revealed on USG was 6.8 $\mathrm{mm} \pm 3.8 \mathrm{~mm}$ and the mean size of the renal calculus not imagined on USG but identified on CTU was $3.5 \mathrm{~mm} \pm 2.7 \mathrm{~mm}$. The sensitivity and specificity of ureteric calculi finding on USG were $12 \%$ and $97 \%$ respectively. The sensitivity and specificity of urinary bladder calculi detection on USG

were $20 \%$ and $100 \%$ respectively.

Conclusion: The presence study revealed that accuracy of US in finding renal, ureteric and urinary bladder calculi were $68 \%$, $80 \%$ and $99 \%$ Respectively.

Keywords: Nephrolithiasis, Ultrasound, Computed Tomography.

\section{INTRODUCTION}

Nephrolithiasis, or kidney stone, is the occurrence of renal calculi produced by an interference in balance between solubility and precipitation of salts in urinary tract and in the kidneys. The frequency is at highest amongst white males age 20 and 30 years old. The prevalence of Nephrolithiasis was $10.1 \%$ for the last 2013-2014 The National Health and Nutrition Examination Survey (NHANES) cycle. The highest prevalence of Nephrolithiasis was seen in males elder than 61 years, at $17.8 \%$, followed by males $40-60$ years old at $12.6 \% .^{1,2}$ Nephrolithiasis is considered to be a disease of affluence like hypertension, obesity and type 2 diabetes as it is predominant in rich countries. ${ }^{3,4}$ Urologic intervention is essential in numerous as $20 \%$ of patients with renal colic and $>2$ billion US dollar is expended on management every year. ${ }^{5}$ The lifetime occurrence of renal calculi in the India is $7 \%$ among female and $12 \%$ among male. ${ }^{6,7}$ Renal calculi progress when urine develops "supersaturated" with insoluble compounds comprising phosphate $(\mathrm{CaP})$ and calcium oxalate $(\mathrm{CaOx})$ resultant from dehydration or a hereditary tendency to over-excrete these ions in the urine. About $5-10 \%$ of Indian have this predisposition. 8,9

Kidney stone formation is an organic procedure that includes physicochemical changes and supersaturation of urine. Supersaturated solution states that includes dissolved solvent under normal circumstances. ${ }^{10}$ As a consequence of supersaturation, solutes precipitate in urine results in nucleation and then crystal concretions are produced. Namely, crystallization appears when concentration of two ions exceeds their saturation point in the solution. ${ }^{11}$ The alteration of liquid to solid phase is influenced by $\mathrm{pH}$ and exact concentrations of extra materials. The level of urinary saturation with respect to stone-forming components like phosphorus, calcium, oxalate, uric acid, cysteine, and low urine quantity are possibility factors for crystallization. ${ }^{12}$ Consequently, crystallization progression varies on thermodynamics (that results in nucleation) and kinetics (which includes rates of nucleation or crystal progression) of a supersaturated solution. ${ }^{13}$ Therefore, lithiasis can be prevented by avoiding supersaturation. 
Ultrasound (USG) is one of the best suitable and beneficial assessment tool it is simply accessible, radiation-free, reproducible, economical and non-invasive. ${ }^{14} \mathrm{~A}$ USG that is negative for calculi might rapid need for unenhanced computed tomography urogram (CTU). CTU was exposed to be extremely sensitive and specific for ureteric calculi. ${ }^{15}$ Its important benefits over other modalities in finding of urolithiasis comprises accuracy, non-usage of intravenous contrast media, in addition to the capabilities to assess secondary consequences of obstacle, and perceive other possible sources of pain but patients are inevitably exposed to radiation. ${ }^{16}$

So, there has been minute direct contrast between USG and CTU in finding of urolithiasis. CTU as existence gold standard, our study intentions were to determine sensitivity of USG in identifying urinary tract calculi. The patients supposed of having renal tract calculi undergo a work-up that comprises KUB radiograph, urine analysis and USG as first line analyses. A positive USG may or may not progress to CTU but all negative USG will undergo CTU for further assessment. But is it really essential for patients to be exposed to the radiation by a CTU? i.e. why, this study has set out to see how many negative USG showed to be positive on CTU.

\section{MATERIALAND METHODS}

This study was approved by the hospital technical and ethical committee. Patient informed consent was obtained as this is a prospective study.

This was a Prospective study involving 150 patients at our centre who had USG and CTU for suspected urinary tract calculi over a period of 1 year, from January 2019 to December 2019. A pilot study conducted in November 2018 showed that 25 patients had CTU during that particular month.

Inclusion Criteria: Patients 25 to 79 years of either sex who reported about their family history of nephrolithiasis, and complaints include flank pain and abdominal pain, haematuria, passing of stone during urination, restless and irritable during urination.

Exclusion Criteria: Men weighing more than $129 \mathrm{~kg}$ and women weighing more than $113 \mathrm{~kg}$ were excluded, since the accuracy of imaging may be reduced in obese patients. Patients who had a single kidney, who had undergone renal transplantation, or who were undergoing dialysis were ineligible.

\section{Examination technique}

CTU was done in the Department of Radiology at our centre using Siemens CT Somatom Sensation 64 with a dedicated protocol. Patient with full urinary bladder was positioned supine on CT examination table and scanned from the upper abdomen to the symphysis pubis with image reconstructed at $5 \mathrm{~mm}$ intervals. No oral or i.v contrast media was given. Calculus was distinct as hyper dense focus in the kidney, ureter and/or bladder. USG was performed using multiple new generation ultrasound scanners (Toshiba, Philips and GE Logic).

Ultrasound included evaluation of the kidneys in multiple anatomic planes and maximum calculus measurement was recorded. Curved-phase array transducers were used with varied transducer frequency depending on the body habitus to optimise both patient penetration and image resolution. Calculus on ultrasound was typically exhibited as highly echogenic focus with definite posterior acoustic shadowing.

\section{STATISTICAL ANALYSIS}

Data was collected from the hospital Integrated Radiology Information System (IRIS) and Picture Archiving and Communication System (PACS). Demographic data including age, sex and ethnicity were gathered. A review of the USG and CTU of each patient was finished with documentation of the imaging findings comprising presence or absence of calculus, location (ureter, kidney or bladder), site (left or right urinary tract or both), and calculus dimension in millimetre. With CTU as the gold standard, sensitivity, specificity, accuracy, positive predictive value and negative predictive value of USG for finding of calculus at each of the three locations (ureter, kidney and bladder) were analysed. Statistical Package for Social Sciences (SPSS) version $25^{\text {th }}$ was used for statistical analyses.

\section{RESULTS}

A total of 150 patients were included in the study.

In table 1 , the patients were predominantly in the late adulthood and elderly age groups, with 50 patients (42\%), 25 patients (31\%) and 35 patients (27\%) aged between 25-39, 40-59 and 60-79 years old respectively. The mean age was 52 years old. Gender wise distribution, there were maximum no. of patients were 87 males and 63 females.

In table 2, from the 150 data collected patients, 45 renal calculi were detected on both USG and CTU. There were 11 false positive cases. The sensitivity and specificity of renal calculi finding on ultrasound were $52 \%$ and $86 \%$ respectively. The positive predictive value (PPV) was $84 \%$ and negative predictive value (NPV) was $57 \%$. The accurateness of ultrasound in detecting renal calculi was $68 \%$. Of the 45 renal calculi detected on USG, 33 calculi were measured. The remaining 7 calculi not measured were too small and defined as tiny or too large and labelled as staghorn calculi.

In table 3 , the majority of calculi noticed by USG measured 5.1-10 $\mathrm{mm}$. The least, extreme and normal size noted was $3.5 \mathrm{~mm}, 22 \mathrm{~mm}$ and $6.8 \mathrm{~mm} \pm 3.8 \mathrm{~mm}$ respectively. 45 renal calculus detected and 38 renal calculi were not detected on USG but positive on CTU and 41 findings were true negative. Of the 38 calculi not detected on USG but detected on CTU, 9 were described as tiny and the other 29 were measured on CTU. The mainstream of calculi not found by USG measured $\leq 5 \mathrm{~mm}$. The least, extreme and normal size of calculi that were not identified on USG was $3 \mathrm{~mm}, 11 \mathrm{~mm}$ and $3.7 \mathrm{~mm} \pm 2.1 \mathrm{~mm}$ respectively.

In table 4 , ultrasound detected only 4 of the 26 ureteric calculi that were detected on CTU giving a low sensitivity of $12 \%$. However, it presented a more specificity of $97 \%$. The accuracy of ultrasound in finding ureteric calculi was $81 \%$. The PPV and NPV were $63 \%$ and $81 \%$ respectively.

On the other hand, detection of urinary bladder calculi for the detection of urinary bladder calculi, ultrasound achieved $20 \%$ sensitivity and 100\% specificity. The PPV was 100\% with NPV of $98 \%$. The accuracy was $98 \%$. 


\begin{tabular}{|l|c|c|}
\hline Age group & No. of patients & Percentage \\
\hline 25-39 Years & 63 & 42 \\
\hline 40-59 Years & 48 & 32 \\
\hline $60-79$ Years & 39 & 26 \\
\hline Sex & & 58 \\
\hline Male & 87 & 42 \\
\hline Female & 63 & \\
\hline \multicolumn{2}{|c|}{ Table 1: Distribution of age groups } \\
\hline
\end{tabular}

\begin{tabular}{|l|c|}
\hline Findings & \% Error in USG \\
\hline True positive & 45 \\
\hline True negative & 38 \\
\hline False positive & 11 \\
\hline False negative & 56 \\
\hline Total & 150 \\
\hline Table-2: Calculi described as staghorn have been classified as \\
$\geq 10.1 \mathrm{~mm}$
\end{tabular}

\begin{tabular}{|l|c|c|}
\hline Calculus size $\mathbf{( m m )}$ & $\begin{array}{c}\text { Number detected } \\
\text { (\%) }\end{array}$ & $\begin{array}{c}\text { Number } \\
\text { undetected (\%) }\end{array}$ \\
\hline$\leq 5$ & $15(33)$ & $33(86)$ \\
\hline $5.1-10$ & $18(40)$ & $4(11)$ \\
\hline$\geq 10.1$ & $12(27)$ & $1(3)$ \\
\hline Total & $45(100)$ & $38(100)$ \\
\hline
\end{tabular}

Table-3: Size of detected and undetected renal calculi on USG

\begin{tabular}{|l|c|c|c|}
\hline \multirow{2}{*}{ USG } & \multicolumn{3}{|c|}{ CTU Percentage } \\
\cline { 2 - 4 } & Normal & Abnormal & Total \\
\hline Normal & 119 & 26 & 145 \\
\hline Abnormal & 1 & 4 & 5 \\
\hline Total & 120 & 30 & 150 \\
\hline Detection of urinary bladder calculi on USG and CTU \\
\hline \multirow{3}{*}{ USG } & \multicolumn{3}{|c|}{ CTU Percentage } \\
\cline { 2 - 4 } & Normal & Abnormal & Total \\
\hline Normal & 145 & 3 & 148 \\
\hline Abnormal & 1 & 1 & 2 \\
\hline Total & 146 & 4 & 150 \\
\hline \multicolumn{2}{|c|}{ Table-4: Detection of ureteric calculi on USG and CTU } \\
\hline
\end{tabular}

\section{DISCUSSION}

This study showed that USG had limited value for the detection of renal calculi. The sensitivity and specificity of $53 \%$ and $85 \%$ respectively were lesser contrast to two earlier studies that had stated $81 \%$ and $100 \%$, and $76 \%$ and $100 \%$ for sensitivity and specificity respectively. ${ }^{17}$ However, our sensitivity exceeded that of another study, which reported a sensitivity of $24 \%$, but a slightly higher specificity of $90 \% .{ }^{18}$ The lengthier time interval between ultrasound and CTU (45\% within 1 month, the rest 1 month or more) in this study could have donated to this difference, in compare to 1 month or less in earlier studies.

The poor sensitivity and the excessive false negative rates (41\%) of USG exhibited in this study are related to multiple factors. Calculi may be missed at USG due to lack of acoustic shadowing of the calculus. ${ }^{19}$ The other factors would be the body habitus, 6 the selection of the transducer power, and focal length. ${ }^{20}$ The excellent contrast resolution of CTU allows discrimination of slight differences in attenuation, allowing better visualisation of stones. Furthermore, CTU has the capacity to obtain a volume of data that comprises the whole urinary system and not just renal only. USG could miss calculi within some parts of the urinary tract, particularly the ureters.

In this study, the false positive rate (FP) was $15 \%$ for USG and may have been due to renal vascular calcification. ${ }^{21} \mathrm{With}$ regard to the size of renal calculi that were detected, this study presented that the mean size of calculi noticed on USG was $7.6 \mathrm{~mm} \pm 4.1 \mathrm{~mm}$, similar to study that stated a mean size of $7.1 \mathrm{~mm} \pm 1.2 \mathrm{~mm} .7$ Of the 53 renal calculi not detected on USG, $85 \%$ measured $\leq 5 \mathrm{~mm}$. A previous study showed that the mean size of calculus detected on CTU was $4.2 \mathrm{~mm} \pm$ $0.4 \mathrm{~mm} .{ }^{22}$ Seventy-three percent of calculi not visualized on USG were $3 \mathrm{~mm}$ or less in size. ${ }^{23}$

The USG in which a $12-\mathrm{mm}$ calculus had been missed but was detected later on CTU was performed by a junior trainee, and the time interval between USG and CTU was between $1-3$ months. The existence of posterior acoustic shadowing depends on size of the calculus. Consequently, lesser the calculus, the more probable it might be missed. ${ }^{24}$ However, the reason for a large calculus not being identified on USG is not clear. One way to improve on USG skill is to repeat the USG whenever a false negative or false positive result is noted on CTU.

With regard to the detection of ureteric calculi, a prospective study in 1998 achieved a sensitivity of $19 \%$ and a specificity of $97 \% .{ }^{25}$ Another study in 2007 showed a slightly higher sensitivity of $23 \%$ and specificity of $100 \%{ }^{26}$ In this study, almost similar results were achieved, with low sensitivity of $12 \%$ and high specificity of $97 \%$. The low sensitivity is attributable to occurrence of bowel gas, which normally obscures the ureters, and more body habitus with dense subcutaneous fat that decreases visibility. ${ }^{27}$ The specificity of calculi detection on USG is greater in the ureter than in the kidneys. This is because the identification of ureteric calculus is significantly helped by the occurrence of hydro ureter. ${ }^{28}$ In other words, USG deficits sensitivity for finding of ureteric calculi. However, it is impartially precise when calculi are seen. This study showed the accuracy of USG in detecting renal, ureteric and urinary bladder calculi was $67 \%$, $80 \%$ and $98 \%$ respectively. USG is not equivalent to CTU in detecting urinary tract calculi. Though, this does not mean that all patient suspected of having a urinary tract calculus should undergo a CTU. Based on the findings of this study, the following imaging algorithm is recommended.

A limitation of this study is the extended time interval between ultrasound and CTU. Approximately 55\% of the patients obligated their ultrasound and CTU done at more than 1 month apart. Accuracy of ultrasound could be affected as calculi could have moved or changed in size during this period of time.

New ultrasound technique such as the use of Doppler ultrasound to detect "twinkling artefact" could potentially improve urolithiasis detection on sonography, and should certainly be looked into in future studies. ${ }^{29}$ 


\section{CONCLUSION}

The sensitivity and specificity of USG in detecting renal calculi was $52 \%$ and $86 \%$ respectively and the mean size of renal calculi not visualized on USG was $3.5 \mathrm{~mm} \pm 2.7 \mathrm{~mm}$. Our study showed that the accuracy of USG in detecting renal, ureteric and urinary bladder calculi was $68 \%, 80 \%$ and $99 \%$ respectively.

\section{REFERENCE}

1. Teichman JM. Clinical practice. Acute renal colic from ureteral calculus. N Engl J Med. 2004;350(1):684-693.

2. Durr-E-Sabih, Khan AN, Craig M, Worrall JA. Sonographic mimics of renal calculi. J Ultrasound Med 2004;23(5):1361-7.

3. Ben Nakhi A, Gupta R, Al-Hunayan A, Muttikkal T, Chavan V, Mohammed A, et al. Comparative analysis and interobserver variation of unenhanced computed tomography and intravenous urography in the diagnosis of acute flank pain. Med Princ Pract 2010;19(3):118-21.

4. Smith RC, Rosenfield AT, Choe KA, et al. Acute flank pain: comparison of non-contrast-enhanced $\mathrm{CT}$ and intravenous urography. Radiology. 1995;194(2):789794.

5. Pfister SA, Deckart A, Laschke S, Dellas S, Otto U, Buitrago C, et al. Unenhanced helical computed tomography vs intravenous urography in patients with acute flank pain: Accuracy and economic impact in a randomized prospective trial. Eur Radiol 2003;13(6):2513-20.

6. Dunnick RN, Sandler CM, Newhouse JH, et al. Textbook of Uroradiology, 3rd ed. Philadelphia, PA: Lippincott Williams \& Wilkins; 2001:178-194.

7. Kimme-Smith C, Perrella RR, Kaveggia LP, Cochran S, Grant EG. Detection of renal stones with real-time sonography: Effect of transducers and scanning parameters. AJR Am J Roentgenol 1991;157(4):975-80.

8. Juul N, Holm-Bentzen M, Rygaard H, Holm HH. Ultrasonographic diagnosis of renal stones. Scand J Urol Nephrol 1987;21(5):135-7.

9. Catalano O, Nunziata A, Altei F, et al. Suspected ureteral colic: primary helical CT versus selective helical CT after unenhanced radiography and sonography. AJR Am J Roentgenol. 2002;178(1): 379-387.

10. Dalla Palma L, Pozzi-Mucelli R, Stacul F. Present-day imaging of patients with renal colic. Eur Radiol 2002;12(3):256-7.

11. Ather MH, Jafri AH, Sulaiman MN. Diagnostic accuracy of ultrasonography compared to unenhanced CT for stone and obstruction in patients with renal failure. BMC Med Imaging. 2004;4(6):2.

12. Hoppe B, Kemper MJ. Diagnostic examination of the child with urolithiasis or nephrocalcinosis. Pediatr Nephrol 2010;25(2):403-13.

13. Yilmaz S, Sindel T, Arslan G, et al. Renal colic: comparison of spiral CT, US and IVU in the detection of ureteral calculi. Eur Radiol. 1998;8(4):212-217.

14. Dogan HS, Tekgul S. Management of pediatric stone disease. Curr Urol Rep 2007;8(1):163-73.

15. Sheafor DH, Hertzberg BS, Freed KS, et al. Nonenhanced helical CT and US in the emergency evaluation of patients with renal colic: prospective comparison. Radiology. 2000;217(4):792-797.

16. Rosen CL, Brown DF, Sagarin MJ, Chang Y, McCabe CJ, Wolfe RE. Ultrasonography by emergency physicians in patients with suspected ureteral colic. J Emerg Med 1998;16(6):865-70.

17. Unal D, Yeni E, Karaoglanoglu M, et al. Can conventional examinations contribute to the diagnostic power of unenhanced helical computed tomography in urolithiasis? Urol Int. 2003;70(1):31-35.

18. Henderson SO, Hoffner RJ, Aragona JL, Groth DE, Esekogwu VI, Chan D. Bedside emergency department ultrasonography plus radiography of the kidneys, ureters, and bladder vs intravenous pyelography in the evaluation of suspected ureteral colic. Acad Emerg Med 1998;5(6):666-71.

19. Patlas M, Farkas A, Fisher D, et al. Ultrasound vs CT for the detection of ureteric stones in patients with renal colic. Br J Radiol. 2001;74(2):901-904.

20. Sinclair D, Wilson S, Toi A, Greenspan L. The evaluation of suspected renal colic: Ultrasound scan versus excretory urography. Ann Emerg Med 1989;18(4):556-9.

21. Smith RC, Rosenfield AT, Choe KA, Essenmacher KR, Verga M, Glickman MG, et al. Acute flank pain: Comparison of non-contrast-enhanced CT and intravenous urography. Radiology 1995;194(6):789-94.

22. Ripollés T, Agramunt M, Errando J, et al. Suspected ureteral colic: plain film and sonography vs unenhanced helical CT. A prospective study in 66 patients. Eur Radiol. 2004;14(1):129-136.

23. Sommer FG, Jeffrey RB Jr, Rubin GD, Napel S, Rimmer SA, Benford J, et al. Detection of ureteral calculi in patients with suspected renal colic: Value of reformatted noncontrast helical CT. AJR Am J Roentgenol 1995;165(6):509-13.

24. Smith RC, Verga M, Dalrymple N, McCarthy S, Rosenfield AT. Acute ureteral obstruction: Value of secondary signs of helical unenhanced CT. AJR Am J Roentgenol 1996;167(3):1109-13.

25. de Souza LR, Goldman SM, Faintuch S, et al. Comparison between ultrasound and noncontrast helical computed tomography for identification of acute ureterolithiasis in a teaching hospital setting. Sao Paulo Med J. 2007;125(1):102-107.

26. Smith RC, Verga M, McCarthy S, Rosenfield AT. Diagnosis of acute flank pain: Value of unenhanced helical CT. AJR Am J Roentgenol 1996;166(5):97-101.

27. Chen MY, Zagoria RJ. Can noncontrast helical computed tomography replace intravenous urography for evaluation of patients with acute urinary tract colic? J Emerg Med 1999;17(6):299-303.

28. Erwin BC, Carroll BA, Sommer FG. Renal colic: The role of ultrasound in initial evaluation. Radiology 1984;152:147-50.

29. Hamm M, Wawroschek F, Weckermann D, et al. Unenhanced helical computed tomography in the evaluation of acute flank pain. Eur Urol.2001;39(1):460465.

\section{Source of Support: Nil; Conflict of Interest: None}

Submitted: 28-02-2020; Accepted: 26-03-2020; Published online: 23-04-2020 